\title{
GNB3 C825T Polymorphism and Elite Athletic Status: A Replication Study with Two Ethnic Groups
}

Authors

Affiliations
J. R. Ruiz ${ }^{1}$, N. Eynon ${ }^{2}$, Y. Meckel $^{2}$, C. Fiuza-Luces ${ }^{3}$, C. Santiago ${ }^{3}$, F. Gómez-Gallego ${ }^{4}$, J. Oliveira ${ }^{5}$, A. Lucia ${ }^{6}$

Affiliation addresses are listed at the end of the article
Key words

- genetics

- endurance athletes

- power

- GNB3 C825T polymorphism

accepted after revision

October 21, 2010

Bibliography

DOI http://dx.doi.org/

10.1055/s-0030-1268438

Published online:

November 25, 2010

Int J Sports Med 2011; 32:

151-153 @ Georg Thieme

Verlag KG Stuttgart · New York

ISSN 0172-4622

\section{Correspondence}

\section{Prof. Alejandro Lucia}

Universidad Europea De Madrid Physiology

Villaviciosa de Odón

28670 Madrid

Spain

Tel.: + 34/916/647800

Fax: + 34/916/168 265

alejandro.lucia@uem.es

\section{Abstract}

$\nabla$

We aimed to replicate the original findings by Eynon et al. [4] showing an association between the T allele of the GNB3 C825T polymorphism and elite endurance athletic status, in larger cohorts and in other ethnicities. We compared allelic and genotypic frequencies of the GNB3 C825T polymorphism among non-athletic controls $(\mathrm{N}=340)$, elite endurance athletes $(\mathrm{N}=174)$, and power athletes $(\mathrm{N}=134)$. The population sample included participants from 2 different ethnic/geographic backgrounds (Israel and

\section{Introduction}

A large number of hormones, neurotransmitters, chemokines, local mediators, and sensory stimuli exert their effects on cells and organisms by binding to heterotrimetric $G$ protein-coupled receptors [7, 12]. Heterotrimeric $G$ proteins transduce ligand binding to these receptors into intracellular signal responses, which underlie numerous physiological responses of tissues and organisms $[7,12]$.

The functional C825T polymorphism [rs5443] in exon 10 of the human guanine nucleotide binding protein $\beta$ protein polypeptide 3 (GNB3) gene, which encodes the $G \beta 3$ subunit of $G$ proteins was described by Siffert and co-workers [18]. The $825 \mathrm{~T}$ allele is associated with alternative splicing of the gene and formation of a truncated but functionally active $\beta 3$ subunit and with enhanced $G$ protein activation [18]. This polymorphism has been associated with multigenic disorders [19], including hypertension [1], and it seems to be a candidate for explaining human variability in exercise phenotypes.

The GNB3 C825T polymorphism plays a minor role in heart rate and body fatness regulation in blacks, as well as in responsiveness of resting
Spain). We observed no significant differences in genotypic and allelic frequencies between countries or groups (all $\mathrm{P}>0.1$ ). The odds ratio (OR) of being an endurance athlete if the subject had a T allele was 0.841 (95\%CI: $0.638-1.110$ ) compared to the control group and 1.047 (95\% CI: 0.751-1.461) compared to the power group. Our findings support the need to corroborate genotype:phenotype associations in the field of sports genetics with the largest possible population samples, including populations of different ethnic backgrounds.

blood pressure to endurance training in black women [14]. It is associated with $\mathrm{VO}_{2 \max }$ in nonathletes [5], and Eynon et al. recently reported a higher frequency of the TT genotype in Israeli elite endurance athletes than in sprinters of the same origin [4]. Whether the latter results can be extrapolated to other populations remains to be elucidated. This is a question of interest because differences among the findings of studies in the field of genetics and sports performance are partly attributable to the different sizes and ethnic/geographic origin of the study populations. To replicate these findings we compared allelic and genotypic frequencies of the GNB3 C825T polymorphism among (Caucasian) controls, elite endurance athletes, and power athletes in subjects from Israel and Spain.

\section{Methods}

$\nabla$

The study was approved by the Helsinki Committee of the 'Hillel-Yaffe' Medical Center (Hadera, Israel), and by the institutional ethics committee of the Universidad Europea de Madrid (Madrid, Spain), according to the Declaration of Helsinki. A written informed consent was obtained from 
each participant. Our study was performed according to ethical standards in sport and exercise science research [8].

\section{Subjects from Israel}

A total of 155 elite athletes (199 men and 36 women, age 18-80 years) volunteered to participate in the study. Athletes were included in the study sample only if they had participated in national/international track and field championships. Athletes were divided into 2 groups: i) endurance athletes (i.e., 74 long distance runners whose main event was the $10000 \mathrm{~m}$ run and the marathon, and ii) power athletes (i.e., 81 sprinters whose main event was the $100-200 \mathrm{~m}$ dash). The control group consisted of 240 non-athletic Israeli healthy individuals (167 men and 73 women, age 19-79 years) who did not engage in physical activity on a regular basis. All subjects (athletes and controls) were Israeli Caucasians, with an equivalent ratio of nonAshkenazi and Ashkenazi descent in each group (2:1).

\section{Subjects from Spain}

The Spanish population comprised: (i) 100 male endurance athletes aged 20-39 years who competed within the last 10 years (50 world-class endurance runners, including Europe champions and Olympic finalists, and 50 professional road cyclists who were all Tour de France finishers, including top-3 finishers; (ii) 53 male power athletes (jumpers, throwers and sprinters) aged 20-33 years who also had competed within the last 10 years: 40 top national level with experience in international competitions and 13 Olympic level, including Olympic finalists; and (iii) 100 healthy male non-athletic controls (not engaged in physical activity on a regular basis; age 19-32 years). All controls and athletes were of the same Caucasian (Spanish) descent for at least 3 generations.

\section{Genotyping}

We extracted DNA from saliva or blood samples between 2004 and 2009. In the samples from Israeli subjects, genotyping of the GNB3 C825T polymorphism was performed using polymerase chain reaction-restriction fragment length polymorphism [13]. In the samples from Spanish subjects, genotyping was performed using a newly-developed low-density DNA microarray based on allele-specific probes [6].

\section{Data analysis}

All statistical analyses were performed using the PASW (v. 18.0 for WINDOWS, Chicago). We used the $X^{2}$ test to compare the genotypic and allelic frequency of the GNB3 C825T polymorphism (rs5443) between the non-athletic controls of both nationalities. Thereafter we used the same test to compare the genotypic and allelic frequency of the following 3 groups: (i) all endurance athletes $(\mathrm{N}=174)$, (ii) all power athletes $(\mathrm{N}=134)$, and (iii) all controls $(\mathrm{N}=340)$. The level of significance was set at 0.05 . Further, we performed logistic regression analysis to examine the association between genotypes and sports performance after controlling for sex and country.

\section{Results}

$\nabla$

When joining subjects from the 2 nationalities, genotype distributions were in Hardy-Weinberg equilibrium in the control group and in the endurance group $(P>0.1)$, but not in the power group $(\mathrm{P}=0.03)$. There were no country differences in the genotypic and allelic frequencies (all $\mathrm{P}>0.1$ ). Table 1 shows the genotype frequencies of the study polymorphism in the 3 groups. We observed no significant differences in genotypic ( $\bullet$ Table 1 ) and allelic ( $\bullet$ Fig. 1 ) frequencies among groups (all $P>0.1$ ). The odds ratio (OR) of being an endurance athlete if the subject had a T allele was 0.841 (95\% confidence interval: $0.638-$ 1.110) compared to the control group, and 1.047 (95\% confidence interval: 0.751-1.461) compared to the power group.

\section{Discussion}

$\nabla$

The GNB3 T allele might be theoretically advantageous for endurance exercise, as it is associated with higher adrenergic activation, and thus with increased mobilisation of circulating fatty acids and glucose that can be oxidised by muscle fibres [4]. However, the previous association reported by Eynon et al. [4] between the GNB3 TT genotype and elite endurance athletic status, with increased $G$ protein activity theoretically increasing the likelihood of being a top-level endurance athlete, was not corroborated here in a larger cohort that also included athletes of another ethnic/geographic origin. This finding supports the need to corroborate genotype:phenotype associations in the field of sports genetics with the largest possible population samples, including cohorts of different ethnic backgrounds. In fact, significant discrepancies exist between studies on the GNB3 C825T polymorphism and disease phenotypes, which are partly attributable to between-studies differences in the sample size and ethnic background of the cohorts. The association between the $\mathrm{T}$ allele and essential hypertension reported in whites $[2,17,18]$ and blacks $[3]$ has not been corroborated in Asian and American Indian populations $[10,11]$. In a large cohort of Japanese diabetic patients, the 825CC genotype rather than the 825CT genotype was associated with hyperlipidemia [9]. It must be kept in mind that achieving elite athletic status (either in power or endurance events) is a complex trait involving the interaction of numerous phenotypes that are not simply reducible to substrate availability (e.g. cardiopulmonary function,

Table 1 Genotypic and allelic frequencies of the GNB3 C825T polymorphism ( $r 55443)$ in controls ( $n=340)$, elite endurance athletes ( $n=174)$ and elite power athletes $(n=134)$.

\begin{tabular}{|c|c|c|c|c|c|c|c|}
\hline Genotype & $\begin{array}{l}\text { Controls } \\
\text { (C) }\end{array}$ & $\begin{array}{l}\text { Endurance } \\
\text { (E) }\end{array}$ & $\begin{array}{l}\text { Power } \\
\text { (P) }\end{array}$ & $\begin{array}{l}\text { Overall } \\
P \text {-value }\end{array}$ & $\begin{array}{l}\text { OR } \\
\text { C vs. E }\end{array}$ & $\begin{array}{l}P \text {-value } \\
\text { C vs. P }\end{array}$ & $\begin{array}{l}P \text {-value } \\
\text { E vs. P }\end{array}$ \\
\hline CC & $38.8(132)$ & $32.8(57)$ & $33.6(45)$ & $\begin{array}{l}0.577 \\
\left(x^{2}: 2.889\right)\end{array}$ & $\begin{array}{l}0.394 \\
\left(x^{2}: 1.862\right)\end{array}$ & $\begin{array}{l}0.465 \\
\left(x^{2}: 1.534\right)\end{array}$ & $\begin{array}{l}0.759 \\
\left(x^{2}: 0.552\right)\end{array}$ \\
\hline CT & 49.7 (169) & $54.0(94)$ & $56.0(75)$ & & & & \\
\hline TT & $11.5(39)$ & $13.2(23)$ & $10.4(14)$ & & & & \\
\hline
\end{tabular}




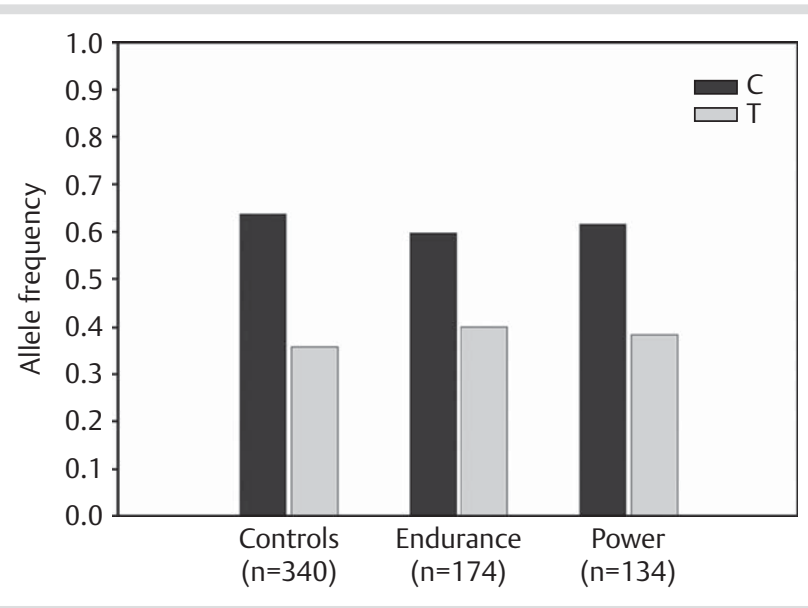

Fig. 1 Allelic GNB3 C825T polymorphism (rs5443) in controls, elite endurance athletes, and elite power athletes. All $\mathrm{P}>0.1$ for frequency comparison among groups.

blood oxygen transport capacity, muscle contractility, etc). Thus, rather that the individual effect of a given polymorphism, it is likely the combined influence of several genetic variants, each with a significant contribution, as well as the complex interaction of genetic variants (with or without an individual contribution) that explain individual variations in endurance/power performance $[15,16,20]$. Further research models in the field of sports genetics should thus account for the polygenic nature of sports related phenotypes. Future replication studies might also determine if the polygenic profile of elite athletes (and the combined influence of genetic polymorphisms on their performance status) differs among ethnicities.

In summary, we did not find an association between the GNB3 C825T polymorphism and elite athletic status in a large population sample that included top-level athletes of 2 different geographic/ethnic backgrounds.

\section{Acknowledgement}

This study was partially supported by the 'Fondo de Investigaciones Sanitarias (FIS \#PS09/00194)'.

\footnotetext{
Affiliations

${ }^{1}$ Unit for Preventive Nutrition, Karolinska Institutet, Department of Biosciences and Nutrition at NOVUM, Huddinge, Sweden

${ }^{2}$ The Zinman College of Physical Education and Sports Sciences at the Wingate Institute, Genetics and Molecular Biology, Netanya, Israel ${ }^{3}$ Universidad Europea de Madrid, Biomedicine, Madrid, Spain

${ }^{4}$ Universidad Europea de Madrid, Biomedical Laboratory, Madrid, Spain

${ }^{5}$ University of Porto - Faculty of Sport, Research Centre for Physical Activity,

Health and Leisure, Porto, Portugal

${ }^{6}$ Universidad Europea De Madrid, Physiology, Madrid, Spain
}

\section{References}

1 Bagos PG, Elefsinioti AL, Nikolopoulos GK, Hamodrakas SJ. The GNB3 C825T polymorphism and essential hypertension: a meta-analysis of 34 studies including 14,094 cases and 17,760 controls. J Hypertens 2007; 25: 487-500

2 Benjafield AV, Jeyasingam CL, Nyholt DR, Griffiths LR, Morris BJ. G-protein beta3 subunit gene (GNB3) variant in causation of essential hypertension. Hypertension 1998; 32: 1094-1097

3 Dong Y, Zhu H, Sagnella GA, Carter ND, Cook DG, Cappuccio FP. Association between the C825T polymorphism of the G protein beta3subunit gene and hypertension in blacks. Hypertension 1999; 34: 1193-1196

4 Eynon N, Oliveira J, Meckel Y, Sagiv M, Yamin C, Sagiv M, Amir R, Duarte $J A$. The guanine nucleotide binding protein beta polypeptide 3 gene C825T polymorphism is associated with elite endurance athletes. Exp Physiol 2009; 94: 344-349

5 Faruque MU, Millis RM, Dunston GM, Kwagyan J, Bond VJr, Rotimi CN, Davis T, Christie R, Campbell AL. Association of GNB3 C825T polymorphism with peak oxygen consumption. Int J Sports Med 2009; 30: 315-319

6 Gomez-Gallego F, Ruiz JR, Buxens A, Altmae S, Artieda M, Santiago C, Gonzalez-Freire M, Verde Z, Arteta D, Martinez A, Tejedor D, Lao JI, Arenas J, Lucia A. Are elite endurance athletes genetically predisposed to lower disease risk? Physiol Genomics 2010; 41: 82-90

7 Hamm HE. The many faces of G protein signaling. J Biol Chem 1998; 273: 669-672

8 Harriss DJ, Atkinson G. International Journal of Sports Medicine - Ethical Standards in Sport and Exercise Science Research. Int J Sports Med 2009; 30: 701-702

9 Hayakawa T, Takamura T, Abe T, Kaneko S. Association of the C825T polymorphism of the G-protein beta3 subunit gene with hypertension, obesity, hyperlipidemia, insulin resistance, diabetes, diabetic complications, and diabetic therapies among Japanese. Metabolism 2007; 56: 44-48

10 Hegele RA, Harris SB, Hanley AJ, Cao H, Zinman B. G protein beta3 subunit gene variant and blood pressure variation in Canadian OjiCree. Hypertension 1998; 32: 688-692

11 Kato N, Sugiyama T, Morita H, Kurihara H, Yamori Y, Yazaki Y. G protein beta3 subunit variant and essential hypertension in Japanese. Hypertension 1998; 32: 935-938

12 Neer EJ. Heterotrimeric G proteins: organizers of transmembrane signals. Cell 1995; 80: 249-257

13 Poch E, Gonzalez D, Gomez-Angelats E, Enjuto M, Pare JC, Rivera F, de La Sierra A. G-Protein beta(3) subunit gene variant and left ventricular hypertrophy in essential hypertension. Hypertension 2000; 35: 214-218

14 Rankinen T, Rice T, Leon AS, Skinner JS, Wilmore JH, Rao DC, Bouchard C. G protein beta 3 polymorphism and hemodynamic and body composition phenotypes in the HERITAGE Family Study. Physiol Genomics 2002; 8: 151-157

15 Ruiz JR, Arteta D, Buxens A, Artieda M, Gomez-Gallego F, Santiago C, Yvert T, Moran M, Lucia A. Can we identify a power-oriented polygenic profile? J Appl Physiol 2010; 108: 561-566

16 Ruiz JR, Gomez-Gallego F, Santiago C, Gonzalez-Freire M, Verde Z, Foster C, Lucia A. Is there an optimum endurance polygenic profile? J Physiol 2009; 587: 1527-1534

17 Schunkert H, Hense HW, Doring A, Riegger GA, Siffert W. Association between a polymorphism in the $G$ protein beta3 subunit gene and lower renin and elevated diastolic blood pressure levels. Hypertension 1998; 32: 510-513

18 Siffert W, Rosskopf D, Siffert G, Busch S, Moritz A, Erbel R, Sharma AM, Ritz E, Wichmann HE, Jakobs KH, Horsthemke B. Association of a human G-protein beta3 subunit variant with hypertension. Nat Genet 1998; 18: $45-48$

19 Weinstein LS, Chen M, Xie T, Liu J. Genetic diseases associated with heterotrimeric G proteins. Trends Pharmacol Sci 2006; 27: 260-266

20 Williams AG, Folland JP. Similarity of polygenic profiles limits the potential for elite human physical performance. J Physiol 2008; 586: 113-121 